\title{
Uncovering drivers of juvenile coral density following mass bleaching
}

\author{
Jan-Claas Dajka ${ }^{1}$ (1) Shaun K. Wilson ${ }^{2,3} \cdot$ James P. W. Robinson $^{1} \cdot$ \\ Karen M. Chong-Seng ${ }^{4} \cdot$ Alasdair Harris $^{5}$ • Nicholas A. J. Graham ${ }^{1}$
}

Received: 25 October 2018/ Accepted: 27 February 2019/Published online: 6 March 2019

(C) The Author(s) 2019

\begin{abstract}
Thermally induced mass coral bleaching is globally responsible for major losses of coral cover. Coral recovery from mass coral disturbances like the 2016 bleaching event hinges on successful recruitment of new coral colonies to the existing population. Juvenile corals as a life history stage represent survival and growth of new recruits. As such, habitat preferences of juvenile corals and how environmental parameters interact to drive coral recovery following a mass bleaching disturbance are important research areas. To expand our knowledge on this topic, we compared juvenile coral densities from before the 2016 bleaching event with those after the disturbance and identified abiotic and biotic characteristics of 21 reefs in the inner Seychelles that predict juvenile coral densities. Our results show that following the 2016 bleaching event, juvenile coral densities were significantly reduced by about
\end{abstract}

Topic Editor Morgan S. Pratchett

Electronic supplementary material The online version of this article (https://doi.org/10.1007/s00338-019-01785-w) contains supplementary material, which is available to authorized users.

Jan-Claas Dajka

j.dajka@lancaster.ac.uk

1 Lancaster Environment Centre, Lancaster University, Lancaster LA1 4YQ, UK

2 Marine Science Program, Department of Biodiversity, Conservation and Attractions, Kensington, WA 6151, Australia

3 Oceans Institute, University of Western Australia, Crawley, WA 6009, Australia

4 ARC Centre of Excellence for Coral Reef Studies, James Cook University, Townsville, QLD 4811, Australia

5 Blue Ventures Conservation, London N7 9DP, UK
$70 \%$, with a particularly large decline in juvenile Acropora. Macroalgae present a large obstacle to survival of juvenile corals in a post-bleaching setting, but their influence varies as a function of herbivore biomass, reef structure, and reef type. Higher biomass of herbivorous fish weakens the negative effect of macroalgae on juvenile corals, and structural complexity on granitic reefs is a strong positive predictor of juvenile coral density. However, structural complexity on carbonate or patch reefs was negatively related to juvenile coral density, highlighting the importance of considering interactive terms in analyses. Our study emphasises the importance of habitat for juvenile coral abundance at both fine and seascape scales, adding to the literature on drivers of reef rebound potential following severe coral bleaching.

Keywords Coral reef recovery · Recruitment - Coral bleaching $\cdot$ Coral reef ecology $\cdot$ Macroalgae $\cdot$ Seychelles

\section{Introduction}

Mass coral bleaching events resulting from ocean warming have led to significant losses of coral cover across many of the world's reefs (Goreau et al. 2000; Hughes et al. 2017). Coral reefs have the ability to rebound from extensive coral bleaching, but it can take more than a decade for coral cover to reach pre-bleaching levels (Gilmour et al. 2013; Graham et al. 2015). Coral reef recovery depends on the reassembly of the habitat-forming hard coral (scleractinian) community (Connell et al. 1997), driven in part by coral recruitment - the replenishment of the local population by new individuals from within or outside an existing population (Hughes et al. 2010). 
Successful coral recruitment is dependent on several important factors that can result in significant demographic bottlenecks. Firstly, recruitment depends on sufficient supply of coral larvae, requiring inputs of external larvae on well-connected reefs (Hughes and Tanner 2000; Elmhirst et al. 2009) or self-recruitment on geographically isolated reefs (Gilmour et al. 2013). Secondly, availability of suitable benthic space for coral settlement is important (Connell et al. 1997; Diaz-Pulido et al. 2010). Some benthic algae (e.g. turf algae or mature fleshy macroalgae) inhibit larval settlement of corals when the algal beds become too dense (Johns et al. 2018), while other surfaces, such as some crustose coralline algae (CCA), can be preferred settlement sites by coral larvae (Yadav et al. 2016). Thirdly, post-settlement mortality of juvenile corals $(0.5-5 \mathrm{~cm}$; Roth and Knowlton 2009) is high (Hughes et al. 2007). Two major drivers of early post-settlement mortality are competition with other benthic organisms, such as macroalgae (Rasher et al. 2011; Johns et al. 2018), and predation, for instance by corallivores and incidental predation by some herbivores (Cole et al. 2008; Doropoulos et al. 2012). Unstable substrates such as rubble have also been suggested to cause major coral recruit die-offs (Fox et al. 2003; Chong-Seng et al. 2014). Mortality rates gradually reduce with coral growth, and most corals escape mortality once they have reached sizes above $5 \mathrm{~cm}$ (Doropoulos et al. 2015), allowing the corals to grow to reproductive sizes and contribute to the adult population (Hughes et al. 2010; Gilmour et al. 2013).

Coral reefs can recover from extensive coral mortality, provided key factors such as fishing, water quality, and anthropogenic climate change are kept within safe operating spaces (Norström et al. 2016). However, the likelihood of experiencing mass coral bleaching events in the coming decades is increasing (Hughes et al. 2018). A longterm study by Graham et al. (2015) in the inner Seychelles determined the density of juvenile corals as one of the five parameters that can positively predict the rebound potential of mass bleaching-disturbed coral reefs. Initial post-disturbance recovery rates are usually slow, and global average increases in per cent coral cover following mass bleaching are only 3\% (Graham et al. 2011). However, recovery rates can speed up exponentially once juvenile corals have grown into reproducing colonies (Gilmour et al. 2013) to create an efficient positive feedback loop that can result in rapid rates of coral cover expansion (Nyström et al. 2012).

Studies spanning multiple decades demonstrate that corals are affected by abiotic factors such as light, depth, and substratum orientation (Babcock and Mundy 1996; Roth and Knowlton 2009), seawater temperature (Edmunds 2004), or cryptic microhabitat orientation along a depth gradient (Edmunds et al. 2004) during early post- settlement. Some biotic surfaces facilitate juvenile coral growth and survival, such as some CCA species (Arnold et al. 2010; Arnold and Steneck 2011); Yadav et al. 2016), calcareous polychaete worm tubes, biofilms (Arnold et al. 2010), and other coral skeletons (Norström et al. 2006). Conversely, other biotic factors inhibit coral recruitment, for instance macroalgae (Box and Mumby 2007; Arnold et al. 2010; Arnold and Steneck 2011), turf algae, and other invertebrates (Arnold et al. 2010; Arnold and Steneck 2011). More recently, interacting biotic processes have been identified, such as between herbivory of turf algae (Arnold et al. 2010) and how herbivore exploitation reduced algal consumption and ultimately affected juvenile coral densities (Steneck et al. 2018).

Despite the extensive body of research, most of our knowledge on the early life history of settled corals does not stem from recently disturbed reefs. With the likelihood of thermally driven coral bleaching events increasing across the tropics (Hughes et al. 2018), an improved understanding of the drivers of post-bleaching coral recruitment will help to identify which processes promote or inhibit coral recovery. A recent study on juvenile coral densities on the Great Barrier Reef following the 2016 bleaching event considered abiotic predictors (temperature, rugosity, location around island, depth) as well as one biotic predictor (coral taxon; Álvarez-Noriega et al. 2018), but post-bleaching influences of other environmental factors, such as herbivory, CCA, or macroalgae, remain unclear. Thus, an important research gap exists regarding post-bleaching habitat and biotic predictors of juvenile coral density. Insight into which cross-scale abiotic and biotic drivers predict juvenile coral densities and how they interact shortly after large-scale coral bleaching events will improve our understanding of how early coral reef recovery dynamics vary spatially following extensive bleaching. Our study addresses this gap by investigating reefs of the inner Seychelles one year after the 2016 bleaching event. We explore temporal patterns of juvenile coral densities before and after the 2016 bleaching event and investigate how key habitat characteristics interact to limit or facilitate juvenile coral density.

\section{Methods}

The inner Seychelles $\left(4^{\circ} 30^{\prime} \mathrm{S}, 55^{\circ} 30^{\prime} \mathrm{E}\right)$ are mostly granitic islands with well-developed carbonate fringing reefs. In recent history, the inner Seychelles' coral reefs have been affected by two major bleaching events caused by thermal anomalies (in 1998: 90\% loss, Goreau et al. 2000; and in 2016: 70\% loss, Wilson et al., in review). We surveyed 21 sites within the inner Seychelles in April 2017, 18 of which had been previously surveyed in 2008 and 2011 . 
At each of the 21 sites, we recorded the abundances of diurnally active, non-cryptic, reef-associated fish species along with estimates of their individual total lengths at 8 replicate point counts ( $7 \mathrm{~m}$ radius) along the reef slope. We excluded any individual fish entering the cylindrical area once sampling had commenced from abundance estimates. To ensure accurate length estimates of fish, the surveying diver estimated the lengths of sized PVC pipes until accuracy was consistently within $4 \%$ of actual lengths every day (Graham et al. 2007). After the survey, we converted estimated fish lengths from surveys into biomass using published length-weight relationships (Letourneur et al. 1998; Froese and Pauly 2018) and species assigned to feeding groups based on their diet and feeding behaviour (Wilson et al. 2008). Within the same point counts, we visually estimated the structural complexity of the reef using a scale from 0 (no vertical reef) to 5 (exceptionally complex with numerous caves and overhangs) as per Polunin and Roberts (1993), which correlates strongly with a range of other methods for capturing the structural complexity of coral reefs (Wilson et al. 2007). We counted sea urchin abundance (family: Diadematidae) within each point count area. Lastly, we randomly deployed a $50 \times 50 \mathrm{~cm}$ quadrat repeatedly within each point count and counted juvenile corals in it. The number of quadrat deployments in each point count area and associated juvenile coral counts was limited to the maximum number that could be deployed within $8 \mathrm{~min}$ (3-13 quadrats per point count). Prior surveys of juvenile corals at these sites in 2008 and 2011 had used quadrat sizes of $33 \times 33 \mathrm{~cm}$ for juvenile density (Chong-Seng et al. 2014; Harris et al. 2014); however, we used larger $50 \times 50 \mathrm{~cm}$ quadrats to obtain a better assessment of the habitat surfaces around juvenile corals. We searched each quadrat for juvenile corals with diameters up to $5 \mathrm{~cm}$ (Roth and Knowlton 2009), identified the corals to genus level, and measured their diameter to the nearest $0.1 \mathrm{~cm}$. Colonies clearly resulting from shrinkage, fragmentation, or overgrowth of older colonies were not recorded (Hughes and Jackson 1985). We recorded the coral's attachment substrate and took a HD photograph of each quadrat from above in a way that all borders of the quadrat were visible. We later analysed the photographs with Coral Point Count with extension for Excel (CPCe; Kohler and Gill 2006) to obtain percent cover values for the benthos categories: macroalgae, turf algae, CCA, sand, rubble, and pavement (bare rock).

\section{Statistical analysis}

We analysed temporal variation in juvenile coral density between 2008 (Harris et al. 2014), 2011 (Chong-Seng et al. 2014), and 2017 at the 18 sites surveyed each year. To standardise varying sampling efforts, we averaged the juvenile coral abundances across quadrats, for each site of each year (18 sites of $3 \mathrm{yr}: n=54)$, rounded to give an average coral abundance. Because different quadrat sizes were used throughout the years, we included the quadrat area as an offset variable, a pre-specified coefficient, in our models. To account for overdispersion of the response variable, we fitted generalised linear mixed models (GLMMs) from the 'lme4' package (Bates et al. 2015) in R (R-Core-Team 2018) for Poisson-distributed errors. Our final models with 'site' as a random intercept term were selected based on Akaike information criterion (AIC; Zuur et al. 2009):

Juvenile coral abundance (All, Acropora, Favites, Porites)

$$
\sim \text { year }+ \text { offset }(\text { area })+(1 \mid \text { site })
$$

We fitted GLMMs to total juvenile corals abundances, as well as to two common genera, Acropora and Porites. For a third genus, Favites, we fitted the same model structure but with Gaussian errors (linear mixed model, LMM), using the 'nlme' package (Pinheiro et al. 2018). We conducted Tukey HSD post hoc tests to identify significant year differences.

Using only the dataset for 2017, we analysed the data for 21 sites at the scale of the 7-m-radius point counts to examine abiotic and biotic drivers of juvenile corals after 2016 bleaching. Because multiple quadrats were deployed within each point count, we averaged and rounded the resulting juvenile coral count across quadrats for each point count $(n=168)$. We expected juvenile coral density to be predicted by 7 biotic and abiotic variables measured at different scales (Table 1) and included ecologically sensible two-way interactions between variables. All variables were only weakly correlated, and so the model was not biased by collinearity issues (Zuur et al. 2009). We scaled variables to a mean of 0 and standard deviation of 1 , a recommended approach for multi-model selection which allows for meaningful comparisons of effect sizes when variables are on different scales (e.g. benthic cover in percent vs. structural complexity; Schielzeth 2010). 'Reef type' was originally a categorical variable with three reef types: carbonate, patch, and granite. After isolating the impact of each reef type on juvenile coral densities, granite stood out significantly from the other two reef types. To reduce the variables and interactions considered by our analysis to a number that can be sensibly interpreted with our given number of observations, we replaced 'reef type' as a categorical variable with a binary dummy variable that isolates the granite reef type and groups carbonate and patch reef types. To account for overdispersion and high frequencies of true zeros in the response variable $(45.5 \%)$, we fitted a zero-inflated negative binomial (ZINB) 
Table 1 Biotic and abiotic variables considered in habitat predictor analysis to explain spatial variation in juvenile coral density

\begin{tabular}{|c|c|c|}
\hline Predictor & Rationale & References \\
\hline $\begin{array}{l}\text { Sand and } \\
\text { rubble }\end{array}$ & $\begin{array}{l}\text { Sand or sediment acts as inhibitors to the settlement of coral larvae, } \\
\text { while unstable rubble can induce post-settlement mortality in corals }\end{array}$ & $\begin{array}{l}\text { Fox et al. (2003), Birrell et al. (2005), Chong-Seng } \\
\text { et al. (2014), Risk (2014), Cameron et al. (2016), } \\
\text { Yadav et al. (2016) }\end{array}$ \\
\hline $\begin{array}{l}\text { Crustose } \\
\text { coralline } \\
\text { algae }(\mathrm{CCA})\end{array}$ & $\begin{array}{l}\text { Coral larvae are able to settle and grow on certain CCA species. CCA } \\
\text { can also act as a competitor for space with macroalgae as well as } \\
\text { corals themselves }\end{array}$ & $\begin{array}{l}\text { Buenau et al. (2011), Vermeij et al. (2011), Yadav } \\
\text { et al. (2016) }\end{array}$ \\
\hline Macroalgae & $\begin{array}{l}\text { Macroalgae are among the primary competitors for space with corals } \\
\text { and can also induce post-settlement mortality to corals via physical } \\
\text { and chemical pathways }\end{array}$ & $\begin{array}{l}\text { McCook et al. (2001), Jompa and McCook (2003), } \\
\text { Diaz-Pulido et al. (2010), Johns et al. (2018) }\end{array}$ \\
\hline $\begin{array}{l}\text { Herbivorous } \\
\text { fish biomass }\end{array}$ & $\begin{array}{l}\text { Feeding by herbivorous fish removes algae creating space for corals to } \\
\text { settle and grow. The grazing impact scales with abundance and body } \\
\text { size. Incidental predation by herbivorous fish on coral spat has also } \\
\text { been reported }\end{array}$ & $\begin{array}{l}\text { Bellwood et al. (2004), Lokrantz et al. (2008), } \\
\text { Doropoulos et al. (2012), Mumby et al. (2013), } \\
\text { Graham et al. (2015) }\end{array}$ \\
\hline $\begin{array}{l}\text { Sea urchin } \\
\text { abundance }\end{array}$ & $\begin{array}{l}\text { Similar to herbivorous fish, sea urchins can both facilitate and limit coral } \\
\text { recruitment by (1) grazing algae that otherwise block potential coral } \\
\text { settlement space and (2) incidental predation on coral spat }\end{array}$ & $\begin{array}{l}\text { Glynn et al. (1979), Carpenter and Edmunds } \\
\text { (2006), Furman and Heck (2009), Edgar et al. } \\
\text { (2010), Hughes et al. (2010) }\end{array}$ \\
\hline $\begin{array}{l}\text { Structural } \\
\text { complexity }\end{array}$ & $\begin{array}{l}\text { Structurally complex reefs provide habitable space for a diverse range of } \\
\text { organisms including fish or sea urchins and create niche space for } \\
\text { coral settlement and survival }\end{array}$ & $\begin{array}{l}\text { Vergés et al. (2011), Graham and Nash (2013), } \\
\text { Rogers et al. (2014), Doropoulos et al. (2016) }\end{array}$ \\
\hline Reef type & $\begin{array}{l}\text { Three reef types were surveyed: carbonate, patch, and granite reefs; reef } \\
\text { type can affect coral recruitment success }\end{array}$ & $\begin{array}{l}\text { Jennings et al. (1995), Graham et al. (2007), Burt } \\
\text { et al. (2009), Wilson et al. (2012) }\end{array}$ \\
\hline
\end{tabular}

regression model via maximum likelihood estimation (Zuur et al. 2012). This is a two-part model that fits two distributions to the data-the first part fits a binomial distribution to the full dataset, treating the response variable as presence-absence data (zero component), while the second part fits a negative binomial distribution to all nonzero response data (i.e. where juvenile corals were present, count component). We initially fitted a zero-inflated mixed model ('site' as random factor) using the glmmTMB package (Brooks et al. 2017) and one without a random effect using the 'pscl' package (Zeileis et al. 2008). Model selection based on AIC (Zuur et al. 2009) classed the model without random effect as better performing, indicating that auto-correlation does not bias our parameter estimates. One variable ('sea urchins') was excluded in backward selection based on AIC, resulting in the final model:

$$
\begin{aligned}
& \text { Juvenile coral density } \sim \text { Sand and rubble }+ \text { CCA } \\
& + \text { macroalgae }+ \text { herbivores }+ \text { complexity } \\
& + \text { reef type }+ \text { reef type } * \text { complexity } \\
& + \text { macroalgae } * \text { complexity }+ \text { macroalgae } * \text { herbivores }
\end{aligned}
$$

The model validation of this final model did show a slight residual clustering in the model's zero component which can be the case with zero-inflated models (Zuur et al. 2012). We visualised predicted relationships in ZINB models by predicting juvenile coral density across the observed range of each variable, holding all other variables to constant means of 0 (Schielzeth 2010). All statistical analyses were conducted in $\mathrm{R}$ (R Core Team 2018). We provide our R-scripts and model predictions at an opensource repository (https://github.com/JanDajka/SeyBabies2016-bleaching).

\section{Results}

\section{Temporal patterns}

Juvenile coral abundances in 2017 were less than half that of previous years (Fig. 1a, GLMM, $z=-9.19$, $p<0.001$ ). A post hoc test (Table S1) showed that 2017 abundances were significantly lower than those of 2008 (Tukey HSD, Z- $\Delta=9.19, p<0.001$ ) and 2011 (Z$\Delta=9.99, p<0.001$ ), while 2008 and 2011 were not significantly different $(\mathrm{Z}-\Delta=-0.912, p=0.63)$. This pattern was also the case for Acropora and Porites coral genera (Fig. 1b, Acropora 2008-2017: Z- $\Delta=3.82, p<0.001$; Acropora 2011-2017: Z- $\Delta=3.95, p<0.001$; Acropora 2008-2011: Z- $\Delta=-0.31, p=0.95$; Porites 2008-2017: $\mathrm{Z}-\Delta=4.82, p<0.001 ;$ Porites 2011-2017: $\mathrm{Z}-\Delta=4.48$, $p<0.001$; Porites 2008-2011: Z- $\Delta=0.53, p=0.86$ ). Juvenile Favites abundances did not significantly differ between the years (Favites 2008-2017: Z- $\Delta=2.29$, 
Fig. 1 Average juvenile coral densities per square metre $( \pm \mathrm{SE})$ of all sampled coral genera from 2008, 2011, and 2017 (a); average juvenile coral densities $( \pm \mathrm{SE})$ of common coral genera Acropora, Favites, and Porites from 2008, 2011, and 2017 (b)
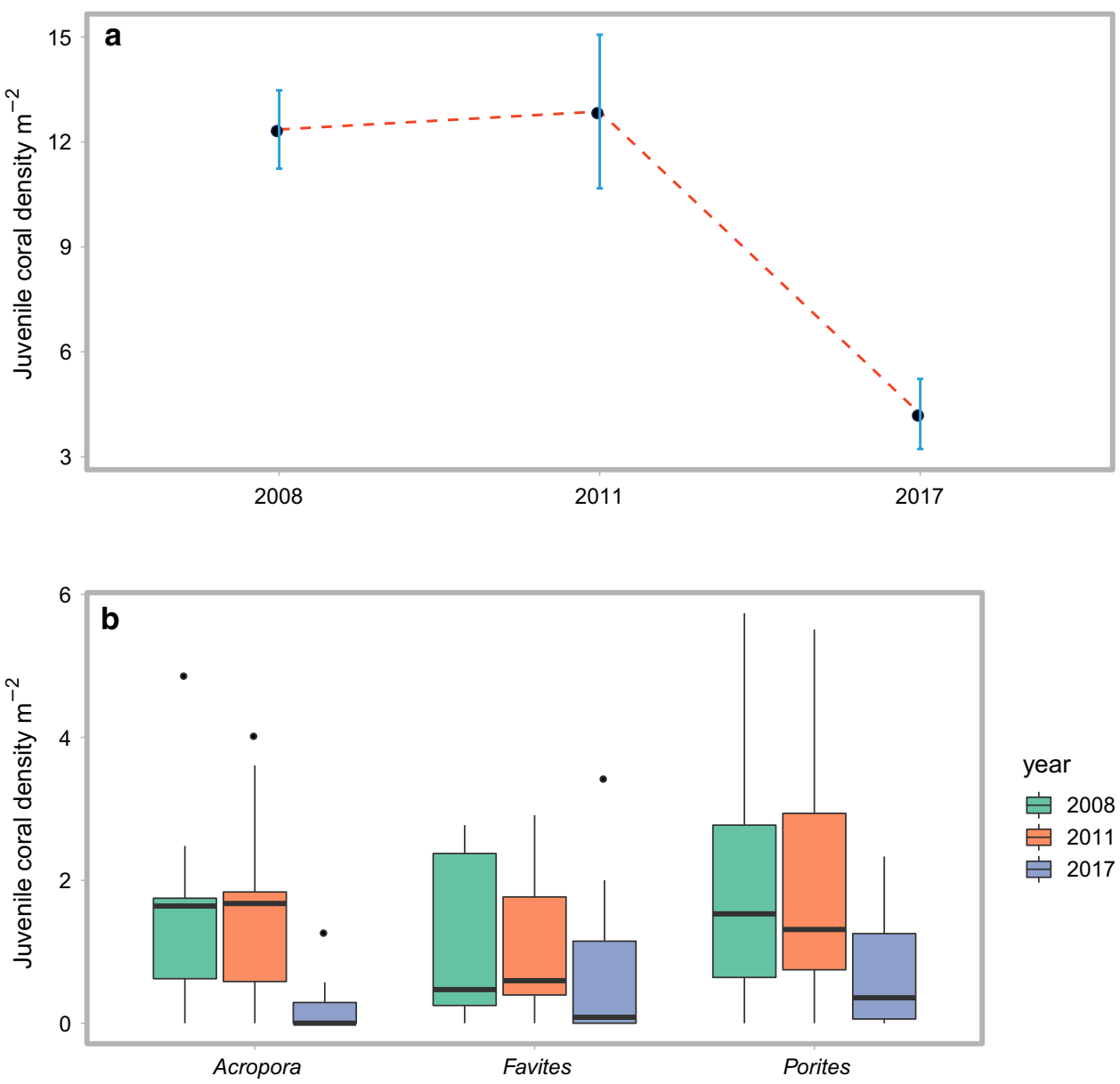

$p=0.072 ;$ Favites 2011-2017: Z- $\Delta=2.4, \quad p=0.056$;

Favites 2011-2008: $\Delta=-0.07, p=0.997)$.

\section{Habitat predictors}

Presence-absence data (zero model) indicated a negative effect of herbivores on juvenile corals (Fig. 2a). Sand and rubble, granitic reef type, and macroalgae had very weak effects on juvenile coral densities, while CCA and complexity had positive effects. All interactions had a positive effect on coral densities. The interaction 'macroalgae * herbivores' highlighted a positive indirect effect of herbivores on juvenile coral densities. The 'macroalgae * complexity' interaction showed how macroalgae slightly reduced the positive effect that complexity alone had on juvenile coral densities while a granitic reef type increased the positive effect for complexity.

In the count component of the model, macroalgae, sand and rubble, and complexity had negative effects on juvenile coral densities (Fig. 2b). CCA and granitic reef type had very weak effects, while herbivores had a positive effect on juvenile coral densities. The 'macroalgae * complexity' interaction had a negative effect, the 'granite * complexity' interaction had a very weak effect, and the 'macroalgae * herbivores' interaction had a positive effect on juvenile coral densities.

The zero-inflation model rarely predicted juvenile coral densities when cover of sand and rubble or macroalgae was greater than 50\%; however, when cover of these groups was low, predicted densities reached $\sim 2.5$ juvenile corals $\mathrm{m}^{-2}$ (Fig. 3a, b). In contrast, when CCA was absent, our model predicted $\sim 1.5$ juvenile corals $\mathrm{m}^{-2}$ and an expansion of up to $30 \%$ CCA cover elevated that prediction above 2 juvenile corals (Fig. 3c). The increasing standard error of additional CCA cover (30-60\%) resulting from few occurrences of high CCA cover values does not allow for further interpretation. The model predicted $\sim 1.5$ juvenile corals $\mathrm{m}^{-2}$ when herbivores were absent, and this number stayed relatively constant up to $250 \mathrm{~kg} \mathrm{ha}^{-1}$ herbivore biomass before falling to $\sim 1$ juvenile coral $\mathrm{m}^{-2}$ at $900 \mathrm{~kg} \mathrm{ha}^{-1}$ herbivore biomass (Fig. 3d). Further interpretation of this trend was not warranted due to large standard errors resulting from few occurrences of high herbivore biomass values.

The 'macroalgae * complexity' interaction of our model predicted densities of $\sim 1.2$ juvenile corals $\mathrm{m}^{-2}$ on low 


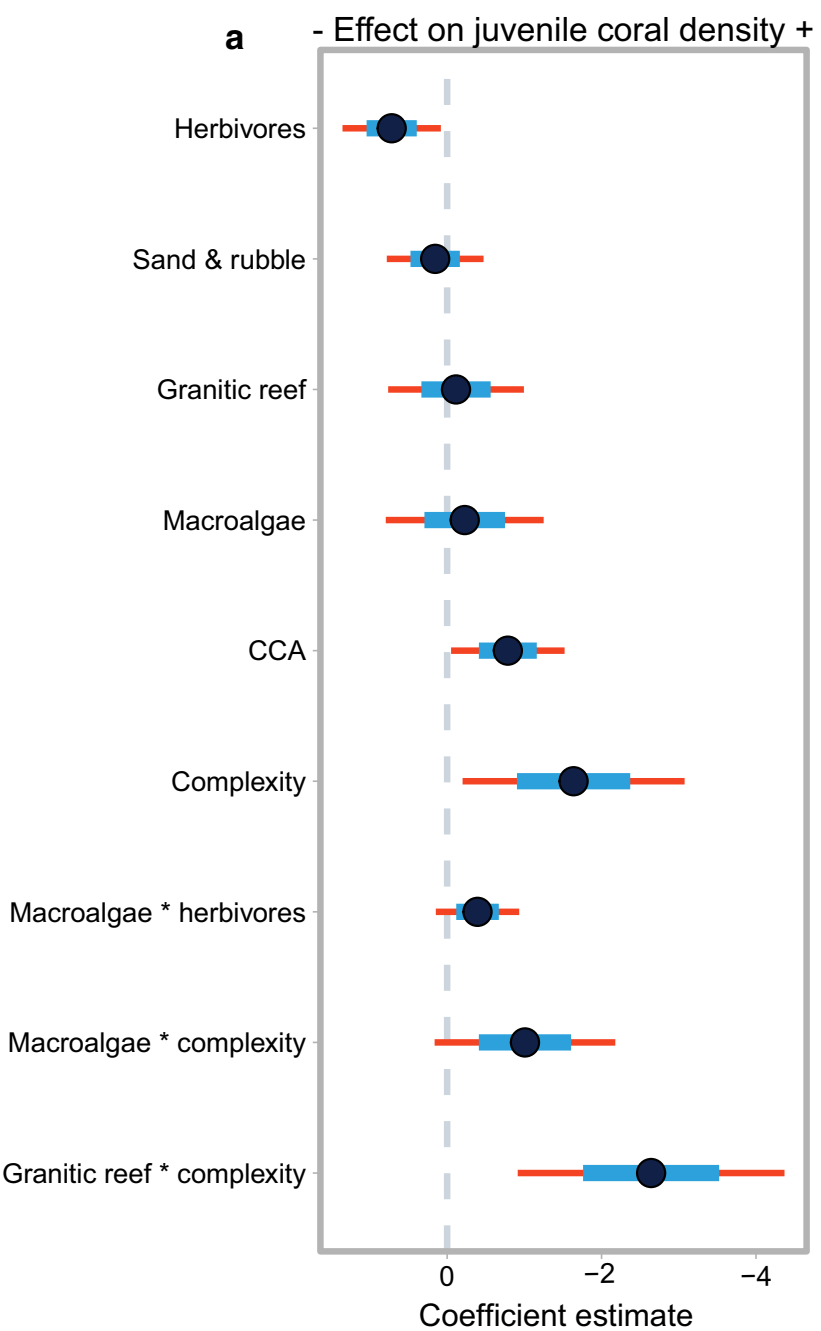

Fig. 2 Effect size estimates of predictor coefficients in zero model with standard error (thick line) and 95\% confidence intervals (thin line); zero model component: positive coefficient estimates predict coral absences ( 0$)$ and negative coefficient estimates predict coral

( $0-1$ on the structural complexity scale)-complexity reefs when macroalgal cover was above $50 \%$, but juveniles were rare on medium (1-3)- or high (3-4)-complexity reefs with macroalgal cover above $50 \%$ (Fig. 4a). When macroalgae cover was low $(\sim 10 \%)$, however, high- and mediumcomplexity habitats supported juvenile coral densities $\sim 5$ juvenile corals $\mathrm{m}^{-2}$, while low-complexity habitats only supported a maximum of $\sim 2.5$ juvenile corals $\mathrm{m}^{-2}$. The prediction of high juvenile coral densities in the highcomplexity habitat at $0 \%$ macroalgae cover was also accompanied by a large standard error resulting from little occurrences of high-complexity habitats without macroalgae in our data and was therefore not interpreted.

The 'macroalgae * herbivore' interaction led to highest densities reaching $\sim 3.5$ juvenile corals $\mathrm{m}^{-2}$ when both macroalgae cover $(5 \%)$ and herbivore fish biomass were low (0-200 kg ha ${ }^{-1}$; Fig. 4b). At low herbivore biomass,

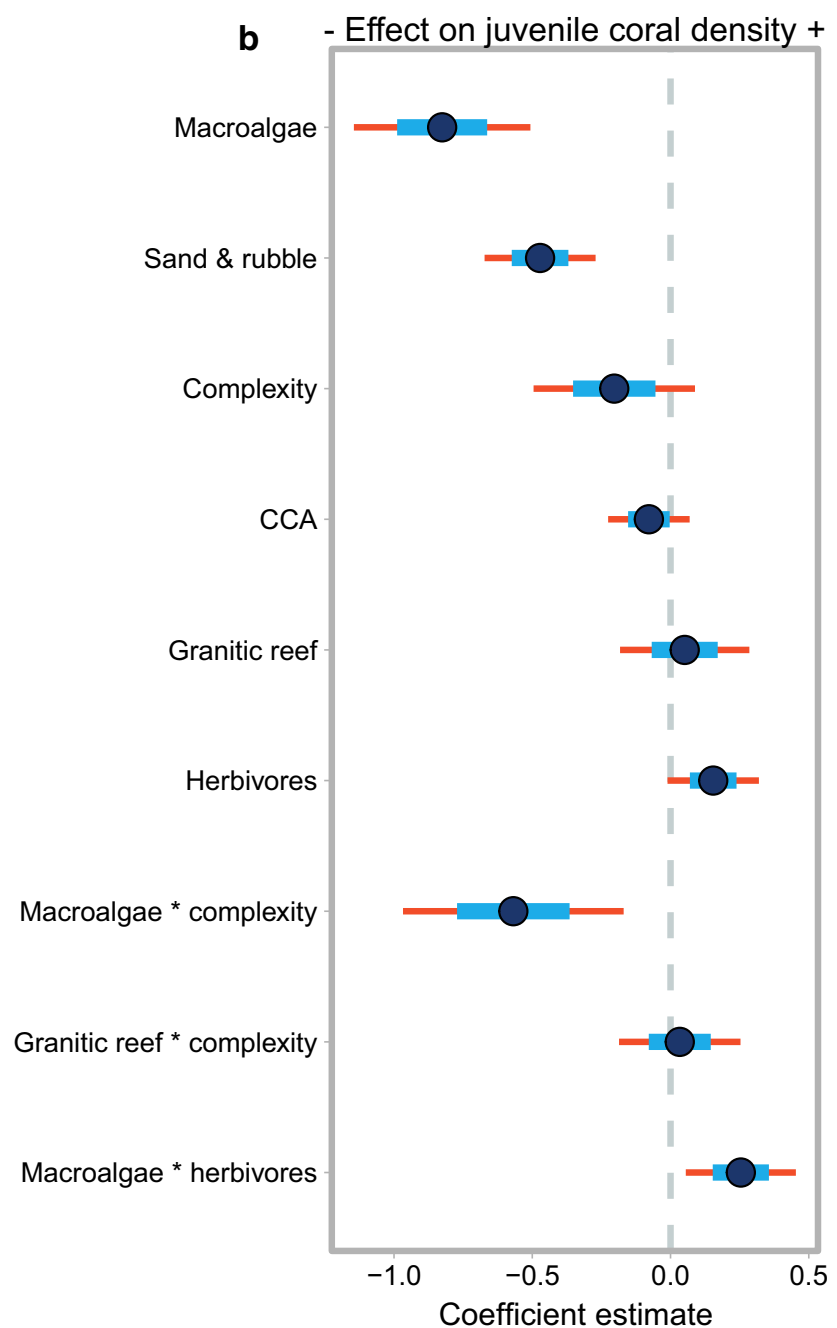

presence (1), stronger negative values indicate stronger positive effect on juvenile coral density (a); count model component: negative coefficient estimates predict lower juvenile coral density and positive coefficients predict higher density (b)

increases in macroalgae cover to $50 \%$ caused a reduction to $\sim 0.5$ juvenile corals $\mathrm{m}^{-2}$. This reduction in juvenile corals occurred at $65 \%$ macroalgae cover at medium (200-400 kg ha ${ }^{-1}$ ) herbivore biomass and to $85 \%$ macroalgae cover at high $\left(400-600 \mathrm{~kg} \mathrm{ha}^{-1}\right)$ herbivore biomass. Yet, the maximum density of juvenile corals was also notably depressed as herbivore biomass increased. When herbivore biomass was low, the model predicted maximum densities of $\sim 3.5$ juvenile corals $\mathrm{m}^{-2}$ and $\sim 3$ juvenile corals $\mathrm{m}^{-2}$ at medium herbivore biomass. At high herbivore biomass, our model only predicted a maximum of $\sim 2.3$ juvenile corals $\mathrm{m}^{-2}$.

For the 'reef type * complexity' interaction, juvenile coral density decreased as complexity increased on carbonate and patch reefs (Fig. 5). For example, in granitic reefs, juvenile corals were absent at low complexity (0-1) but increased from $\sim 0.5$ to 2.2 juvenile corals $\mathrm{m}^{-2}$ at 

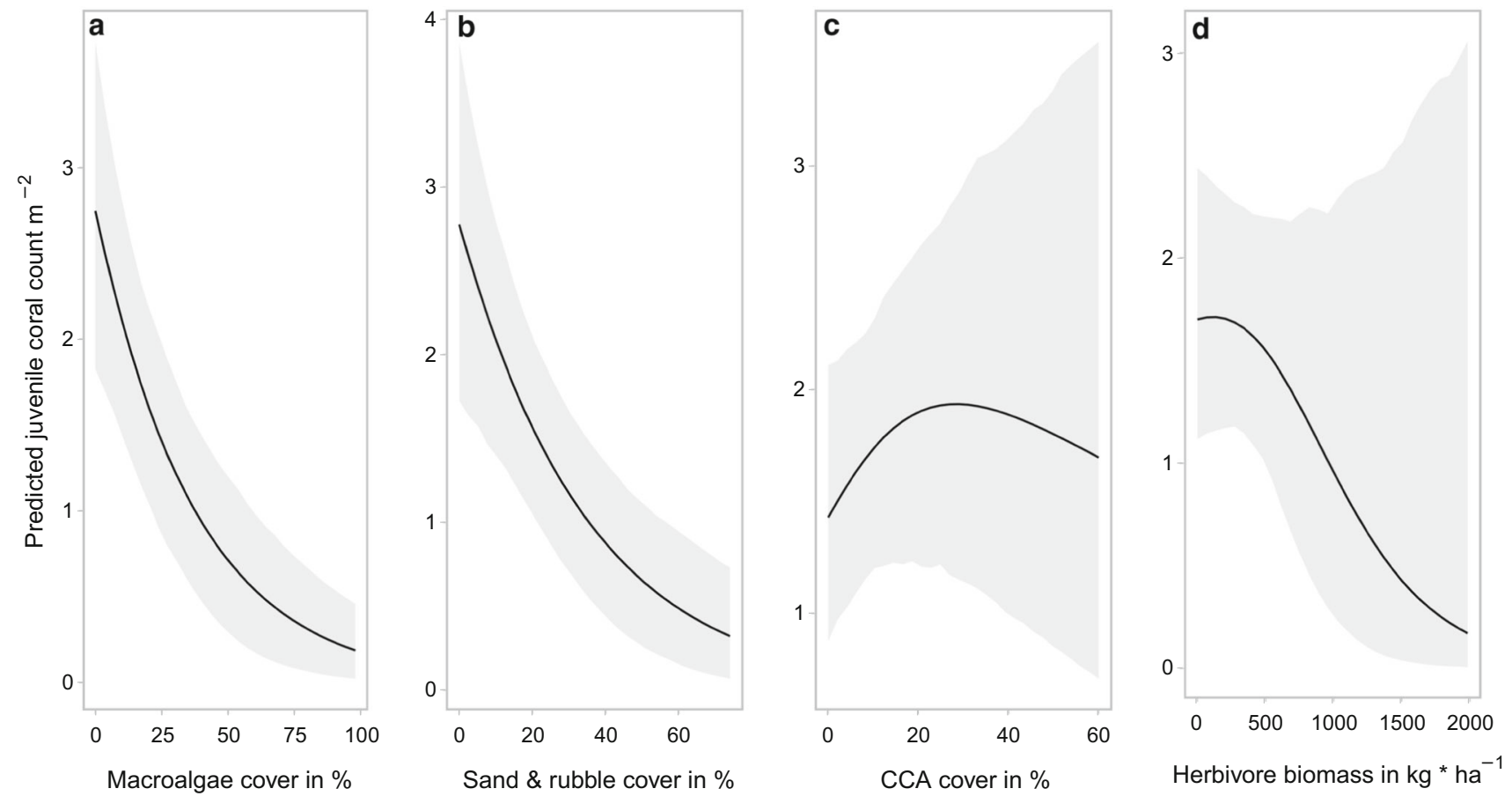

Fig. 3 Model prediction trends of macroalgae (a), sand and rubble (b), CCA (c), and herbivores (d) for the count component of the zero-inflated negative binomial model; panels show the fitted effect (line) and $95 \%$ confidence intervals (shaded bands) for each variable

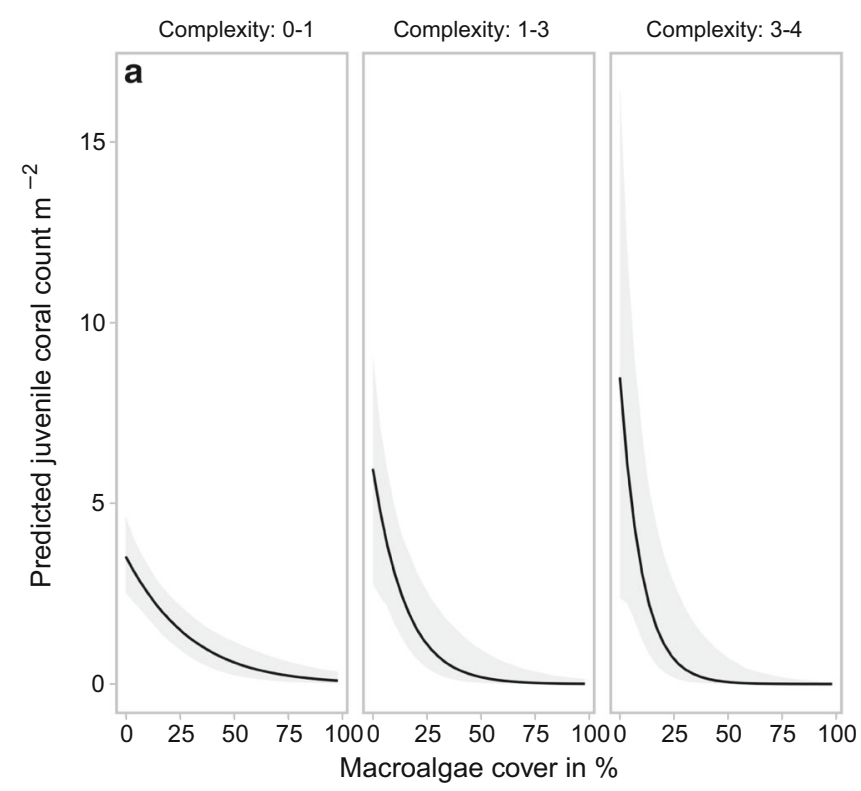

Fig. 4 Model prediction trend for interactions macroalgae * structural complexity (a) and macroalgae * herbivore biomass (b) for the count component of the zero-inflated negative binomial model. Panels

medium complexity (2-3). Both the low-complexity predictions on carbonate and patch reefs and the high-complexity predictions on granitic reefs were accompanied by large prediction uncertainty and were therefore not interpreted.

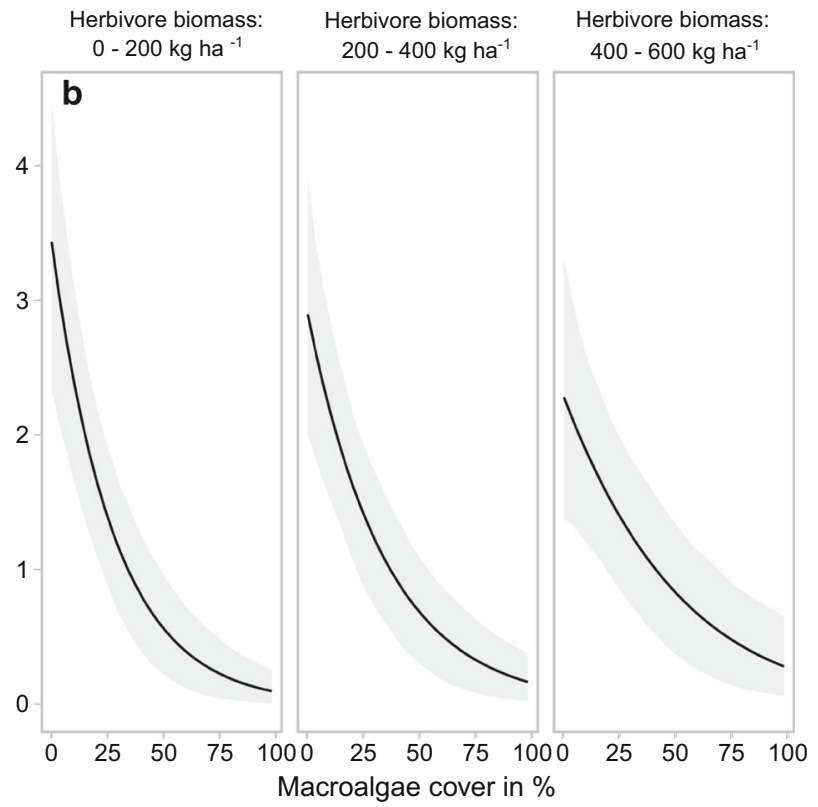

show the fitted effect (line) and 95\% confidence intervals (shaded bands) for each variable

\section{Discussion}

The densities of juvenile corals have been proposed as an important predictor of coral reef recovery from mass bleaching events (Hughes et al. 2010; Gilmour et al. 2013; 


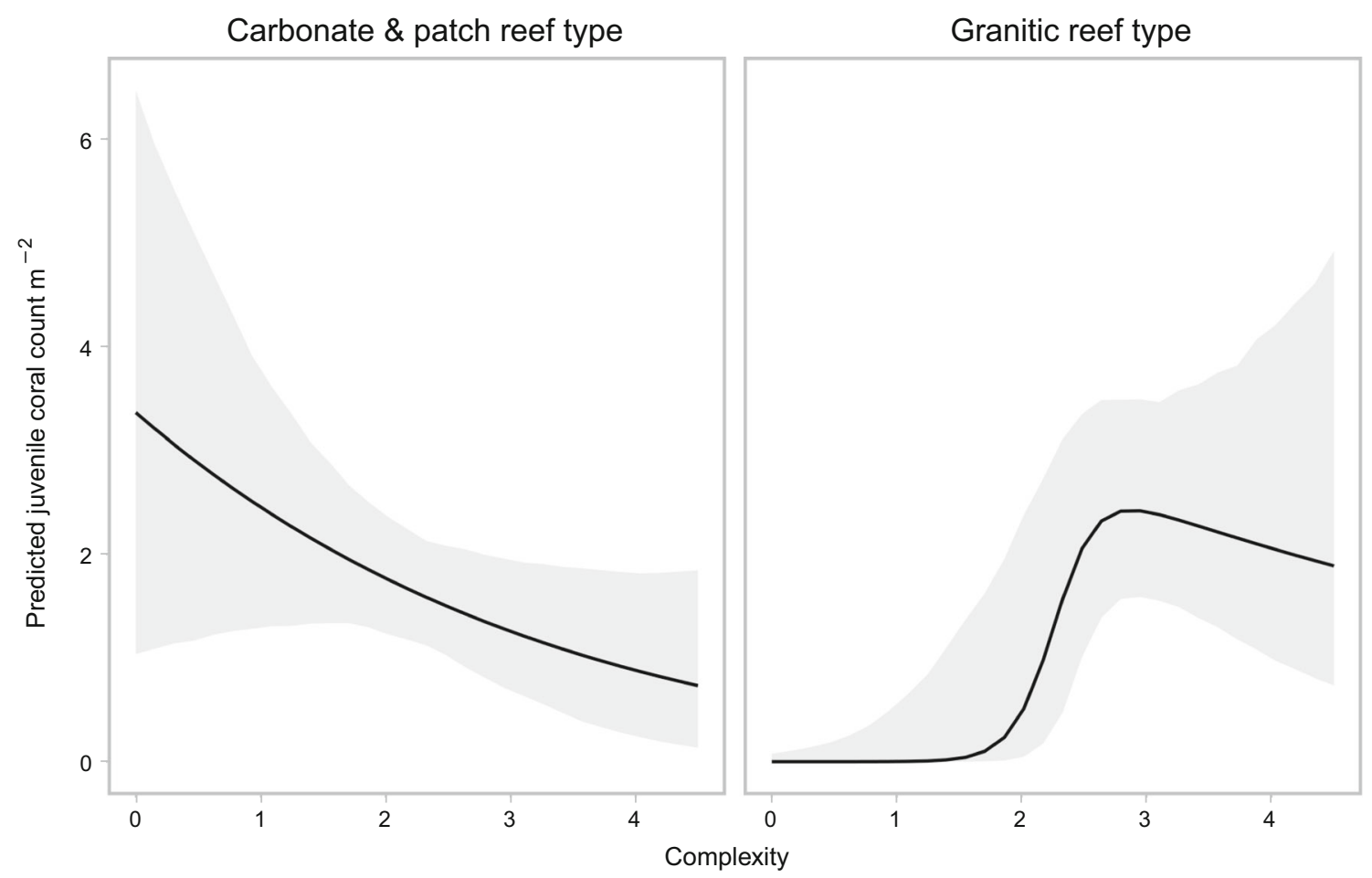

Fig. 5 Model prediction trend for interaction reef type * structural complexity for the count component of the zero-inflated negative binomial model. Panels show the fitted effect (line) and 95\% confidence intervals (shaded bands)

Graham et al. 2015), yet predictors of juvenile corals themselves following large-scale bleaching are hitherto poorly explored. Following the 2016 bleaching event, we recorded a significant reduction in juvenile coral abundance in the inner Seychelles. High cover of macroalgae was associated with few juvenile corals shortly after a mass bleaching event, though interesting nuances were found in how their densities varied with interactions between macroalgal cover and other factors. Macroalgae appear to exploit structurally complex carbonate (limestone) reefs more efficiently and, as a result, may outcompete juvenile corals on these reefs; however, macroalgae cover on highcomplexity granitic reefs is generally low (Graham et al. 2006). Increased biomass of herbivorous fish reduced the negative effect of macroalgae on juvenile corals, though very high biomass of herbivores was associated with slightly lower density of juveniles when macroalgae were absent.

Our temporal findings depict the severity of the 2016 bleaching event to coral recruitment in the inner Seychelles via the loss of $\sim 70 \%$ juvenile coral abundance. This roughly matches the magnitude of adult coral cover loss for the same region (Wilson et al., in review). Loss in adult corals leads to lowered reproductive output and less larval supply (Hughes et al. 2000), which is problematic as the isolated coral communities of the inner Seychelles are likely reliant on self-recruitment (Graham et al. 2006).
Before mass bleaching in 2016, the inner Seychelles' recovery from the 1998 bleaching event was slow for 7-10 years and then sped up exponentially at some sites (Graham et al. 2015), also typical for regions with coral recruitment from local sources (Gilmour et al. 2013). The 2016 bleaching event decimated juvenile Acropora corals. Fast-growing branching corals like Acropora tend to be among the most vulnerable to bleaching (Sheppard et al. 2002; Álvarez-Noriega et al. 2018) but can also drive the bulk of the coral reef's recovery (Emslie et al. 2008; Gilmour et al. 2013; Doropoulos et al. 2015). The low abundance of juvenile corals recorded post-bleaching, paired with their apparent inability to settle or survive on degraded sites (Chong-Seng et al. 2014) and reduced reproductive output of adults, suggests a significant delay of recovery in the inner Seychelles.

Our results indicate that macroalgal cover is a strong negative predictor of juvenile coral density. This supports the widely reported detrimental effect of macroalgae on coral recruitment (Diaz-Pulido et al. 2010; Rasher and Hay 2010; Johns et al. 2018; Steneck et al. 2018) in a postbleaching setting and adds an interesting nuance with two interaction effects. Macroalgae inhibit settlement of coral larvae by blocking space (Diaz-Pulido et al. 2010; Johns et al. 2018) and increase the corals' post-settlement mortality by chemical and physical interference (Tanner 1995; Jompa and McCook 2003; Nugues et al. 2004; Rasher et al. 
2011). It appears that increased structural complexity interacts with macroalgae to the detriment of juvenile corals. This might stem from an increased competitive pressure from macroalgae when coral larvae settle in more complex microhabitats or crevices (Doropoulos et al. 2016), as macroalgae that grow in complex structural elements avoid being grazed by herbivores (Bennett et al. 2010; Poray and Carpenter 2013). Because of the limited space in a crevice, corals experience more contact with macroalgae (Rasher et al. 2011), exacerbating the effects of competition. This is underlined by more complex reefs supporting higher maxima of juvenile coral density when macroalgae cover is low or absent.

Higher biomass of herbivorous fish reduced the detrimental effect of macroalgae expansion on juvenile corals. In Seychelles, herbivorous fish biomass has increased following the 1998 bleaching event and is maintaining a productive inshore fishery (Robinson et al. 2018). Through their increased biomass, herbivorous fish graze more algal mass (Williams et al. 2001) which in turn opens settlement space for coral larvae (Doropoulos et al. 2013) and lessens the contact between corals and algae (Smith et al. 2006; Rasher et al. 2011). Herbivore biomass is a frequently highlighted parameter for coral reef recovery (Bellwood et al. 2004; Mumby et al. 2013) and was also one of the five positive predictors of coral recovery identified for Seychelles (Graham et al. 2015). Additionally, Steneck et al. (2018) found that herbivores reduced the negative effects of macroalgae and consequently had a beneficial effect on juvenile coral density in the Caribbean. In contrast, high herbivore biomass lowered the maximum density of juvenile corals in our study. This could be a result of incidental predation by herbivorous fish on coral spat (Doropoulos et al. 2012). Predation by herbivores, particularly scrapers, but also some grazers and detritivores, largely affects newly settled coral spat. These fish feed on a variety of reef substrates (e.g. turf algae, detritus), inadvertently removing coral recruits. This process largely affects corals within 3 months of settlement when they are still less than a centimetre in diameter, suggesting that predation by herbivorous fish is not visual and hence incidental (Doropoulos et al. 2016). This process might also relate to the macroalgae-complexity interaction, where maximum abundance of juvenile corals at $0 \%$ macroalgae cover appeared depressed in high-complexity habitats compared to medium- and low-complexity habitats. High-complexity habitats typically attract fish, such as corallivores or herbivores, that seek shelter to ensure their own survival (Rogers et al. 2014). Feeding by these fishes can result in targeted or incidental predation on newly settled coral spat (Doropoulos et al. 2012), leading to depressed juvenile coral densities in highly complex reefs without macroalgae.
The presence of rubble and sand was also a strong negative predictor of juvenile coral density. It is well reported that corals experience high post-settlement mortality on unconsolidated surfaces such as sand due to its constant movement with wave energy and ability to smother or crush coral spat (Birrell et al. 2005; Risk 2014; Baldock et al. 2015). Periodic movement is also thought to prevent post-settlement survival of corals on unconsolidated rubble. The constant movement of rubble caused by waves results in newly settled corals being crushed (Fox et al. 2003; Yadav et al. 2016). Rubble was previously highlighted as a cause of serious demographic bottlenecks to corals in the inner Seychelles (Chong-Seng et al. 2014), and both patch and areas of carbonate reefs were often surrounded by sand and rubble (Pers. obs.).

Our data highlight the positive role of crustose coralline algae (CCA) on coral juvenile density. Some species of CCA have been reported to create suitable conditions for corals by acting as settlement cues to coral larvae (RitsonWilliams et al. 2010; Arnold and Steneck 2011; Yadav et al. 2016) or by suppressing macroalgal expansion (Belliveau and Paul 2002; Vermeij et al. 2011). Competition for space has also been reported between corals and CCA-as CCA covers more space, corals run the risk of being overgrown (Buenau et al. 2011). Our results show that CCA can be important for coral replenishment in postbleaching scenarios.

An intriguing finding was the interaction between complexity and reef type. Paired with structural complexity, the granite reef type proved extremely beneficial to juvenile corals. We believe the benefit of granite in our study might be due to it being an unsuitable substrate for macroalgae rather than being a superior substrate for corals (Burt et al. 2009). Macroalgae attach to substrates via holdfasts which can penetrate the substrate up to $10 \mathrm{~mm}$ deep by exploiting the physical characteristics of mineral matrices. The density and matrices of granite and carbonate are very different (Morrison et al. 2009). It is likely that large fleshy macroalgae (e.g. Sargassum, Turbinaria) that commonly outcompete corals on carbonate reefs of the inner Seychelles cannot deeply penetrate the granitic mineral matrix (Milligan and DeWreede 2000), leading to an increased probability of algae dislodging as they grow (Thomsen 2004). Herbivorous fish could be assisting the coral's ability to more successfully exploit structural complexity on granitic reefs. Herbivore fish assemblages on granitic reefs in the inner Seychelles are more stable than those of carbonate and patch reef types (Graham et al. 2006). We found in our study that the average herbivorous fish biomass was very similar for carbonate and patch reef types $\left(\sim 300 \mathrm{~kg} \mathrm{ha}^{-1}\right)$, yet it was slightly elevated in the granite reef type $\left(\sim 400 \mathrm{~kg} \mathrm{ha}^{-1}\right)$. 
Our results have multiple implications for coral reef management. Our study reaffirms the negative effect macroalgae can have on coral recruitment and that reducing the competitive advantage of macroalgae is key to triggering a potential shift back to coral dominance on regime-shifted reefs via the support of positive or destabilising feedback loops (Nyström et al. 2012). Many coral reef systems appear currently locked in degraded states, for instance dominated by macroalgae. To break this locked state and push the system towards coral dominance, some negative feedback loops need to be interrupted and positive loops need to be engaged (Mumby and Steneck 2008). Herbivores can assist this feedback shift-our findings and recent findings from a large-scale study (Steneck et al. 2018) suggest that herbivores have a potential to weaken the effect of macroalgae on coral recruitment. High levels of herbivory also tend to push algal communities towards those dominated by calcareous forms (Littler and Littler 1984; Belliveau and Paul 2002), adding to habitats favouring coral reinforcing feedbacks, underlined by the positive effect of CCA detected in our study. A recent review by Ceccarelli et al. (2018) highlights the potential for physical removal of macroalgae to benefit coral, yet its effectiveness over large spatial and temporal scales will depend on whether the underlying drivers (e.g. eutrophication, overfishing of herbivores, ocean warming) that keep reefs locked in negative or reinforcing feedback loops favouring macroalgal dominance (Johns et al. 2018) are addressed (Norström et al. 2016). Our findings also highlight the importance of complex granite reefs for juvenile corals and that these habitats are potential coral refugia in Seychelles. Maintaining low levels of local stressors on complex granitic reefs may therefore be important for recovery.

Climate change and coral bleaching are reshaping coral reefs to a yet unknown extent. The 2016 bleaching event decimated the juvenile coral community of the inner Seychelles, and concomitant obstacles such as macroalgal expansion have limited the ability for recovery on some reefs. As macroalgae interact with other reef characteristics such as structural complexity, herbivore biomass, and reef type, it becomes apparent that this obstacle has a very nuanced nature and addressing it will not be a straightforward process. If coral reef degradation progresses and the carbonate matrices break down, sand and rubble patches will expand, presenting another obstacle for coral recruitment. Should the more steadfast nature of granitic reefs prove suitable refugia to future corals, a greater understanding of the mechanisms that underlie resilience on these reefs and their potential to re-seed nearby carbonate reefs is required.

Acknowledgements We thank the Seychelles Fishing Authority, Seychelles National ParksAuthority, and Nature Seychelles for logistical support, and Rebecca Fisher and Gareth Williams for help with statistics. We also thank two anonymous reviewers for their helpful comments. This work was supported through grants from the Royal Society (Grant No. 1), the Australian Research Council (Grant No. 2), and a Lancaster University Faculty of Science and Technology (Grant No. 3) PhD studentship.

\section{Compliance with ethical standards}

Conflict of interest On behalf of all authors, the corresponding author states that there is no conflict of interest.

Open Access This article is distributed under the terms of the Creative Commons Attribution 4.0 International License (http://crea tivecommons.org/licenses/by/4.0/), which permits unrestricted use, distribution, and reproduction in any medium, provided you give appropriate credit to the original author(s) and the source, provide a link to the Creative Commons license, and indicate if changes were made.

\section{References}

Álvarez-Noriega M, Baird AH, Bridge TCL, Dornelas M, Fontoura L, Pizarro O, Precoda K, Torres-Pulliza D, Woods RM, Zawada K, Madin JS (2018) Contrasting patterns of changes in abundance following a bleaching event between juvenile and adult scleractinian corals. Coral Reefs 37:527

Arnold SN, Steneck RS, Mumby PJ (2010) Running the gauntlet: inhibitory effects of algal turfs on the processes of coral recruitment. Mar Ecol Prog Ser 414:91-105

Arnold SN, Steneck RS (2011) Settling into an Increasingly Hostile World: The Rapidly Closing "Recruitment Window" for Corals. PLoS ONE 6(12):e28681

Babcock RC, Mundy CN (1996) Coral recruitment: Consequences of settlement choice for early growth and survivorship in two scleractinians. Journal of Experimental Marine Biology and Ecology 206:179-201

Baldock TE, Golshani A, Atkinson A, Shimamoto T, Wu S, Callaghan DP, Mumby PJ (2015) Impact of sea-level rise on cross-shore sediment transport on fetch-limited barrier reef island beaches under modal and cyclonic conditions. Marine Pollution Bulletin 97:188-198

Bates Douglas, Maechler Martin, Bolker Ben, Walker Steve (2015) Fitting Linear Mixed-Effects Models Using lme4. Journal of Statistical Software 67(1):1-48

Belliveau SA, Paul VJ (2002) Effects of herbivory and nutrients on the early colonization of crustose coralline and fleshy algae. Marine Ecology Progress Series 232:105-114

Bellwood DR, Hughes TP, Folke C, Nyström M (2004) Confronting the coral reef crisis. Nature 429:827-833

Bennett S, Vergés A, Bellwood DR (2010) Branching coral as a macroalgal refuge in a marginal coral reef system. Coral Reefs 29:471-480

Birrell CL, McCook LJ, Willis BL (2005) Effects of algal turfs and sediment on coral settlement. Marine Pollution Bulletin 51:408-414

Box SJ, Mumby PJ (2007) Effect of macroalgal competition on growth and survival of juvenile Caribbean corals. Marine Ecology Progress Series 342:139-149

Brooks ME, Kristensen K, van Benthem KJ, Magnusson A, Berg CW, Nielsen A, Skaug HJ, Maechler M, Bolker BM (2017) glmmTMB Balances Speed and Flexibility Among Packages 
for Zero-inflated Generalized Linear Mixed Modeling. The R Journal 9(2):378-400

Buenau KE, Price NN, Nisbet RM (2011) Local interactions drive size dependent space competition between coral and crustose coralline algae. Oikos 120:941-949

Burt J, Bartholomew A, Bauman A, Saif A, Sale PF (2009) Coral recruitment and early benthic community development on several materials used in the construction of artificial reefs and breakwaters. Journal of Experimental Marine Biology and Ecology 373:72-78

Cameron CM, Pausch RE, Miller MW (2016) Coral recruitment dynamics and substrate mobility in a rubble-dominated back reef habitat. Bulletin of Marine Science 92:123-136

Carpenter RC, Edmunds PJ (2006) Local and regional scale recovery of Diadema promotes recruitment of scleractinian corals. Ecology letters 9:271-280

Ceccarelli DM, Loffler Z, Bourne DG, Al Moajil-Cole GS, BoströmEinarsson L, Evans-Illidge E, Fabricius K, Glasl B, Marshall P, McLeod I, Read M, Schaffelke B, Smith AK, Torras Jorda G, Williamson DH, Bay L (2018) Rehabilitation of coral reefs through removal of macroalgae: State of knowledge and considerations for management and implementation. Restoration Ecology 26:827-838

Chong-Seng KM, Graham NAJ, Pratchett MS (2014) Bottlenecks to coral recovery in the Seychelles. Coral Reefs 33:449-461

Cole AJ, Pratchett MS, Jones GP (2008) Diversity and functional importance of coral-feeding fishes on tropical coral reefs. Fish and Fisheries 9:286-307

Connell JH, Hughes TP, Wallace CC (1997) A 30-year study of coral abundance, recruitment, and disturbance at several scales in space and time. Ecological Monographs 67:461-488

Diaz-Pulido G, Harii S, McCook LJ, Hoegh-Guldberg O (2010) The impact of benthic algae on the settlement of a reef-building coral. Coral Reefs 29:203-208

Doropoulos C, Hyndes GA, Abecasis D, Vergés A (2013) Herbivores strongly influence algal recruitment in both coral- and algaldominated coral reef habitats. Marine Ecology Progress Series 486:153-164

Doropoulos C, Ward S, Marshell A, Diaz-Pulido G, Mumby PJ (2012) Interactions among chronic and acute impacts on coral recruits: the importance of size-escape thresholds. Ecology 93:2131-2138

Doropoulos C, Ward S, Roff G, González-Rivero M, Mumby PJ (2015) Linking Demographic Processes of Juvenile Corals to Benthic Recovery Trajectories in Two Common Reef Habitats. Plos One 10:e0128535

Doropoulos C, Roff G, Bozec YM, Zupan M, Werminghausen J, Mumby PJ (2016) Characterizing the ecological trade- offs throughout the early ontogeny of coral recruitment. Ecological Monographs 86:20-44

Edgar GJ, Banks SA, Brandt M, Bustamante RH, Chiriboga A, Earle SA, Garske LE, Glynn PW, Grove JS, Henderson S, Hickman CP, Miller KA, Rivera F, Wellington GM (2010) El Niño, grazers and fisheries interact to greatly elevate extinction risk for Galapagos marine species. Global Change Biology $16: 2876-2890$

Edmunds PJ (2004) Juvenile coral population dynamics track rising seawater temperature on a Caribbean reef. Marine Ecology Progress Series 269:111-119

Edmunds PJ, Bruno JF, Carlon DB (2004) Effects of depth and microhabitat on growth and survivorship of juvenile corals in the Florida Keys. Marine Ecology Progress Series 278:115-124

Elmhirst T, Connolly SR, Hughes TP (2009) Connectivity, regime shifts and the resilience of coral reefs. Coral Reefs 28:949-957

Emslie MJ, Cheal AJ, Sweatman H, Delean S (2008) Recovery from disturbance of coral and reef fish communities on the Great
Barrier Reef, Australia. Marine Ecology Progress Series 371:177-190

Fox HE, Pet JS, Dahuri R, Caldwell RL (2003) Recovery in rubble fields: long-term impacts of blast fishing. Marine Pollution Bulletin 46:1024-1031

Froese R, Pauly D (2018) FishBase (http://www.fishbase.org)

Furman B, Heck KL (2009) Differential impacts of echinoid grazers on coral recruitment. Bulletin of Marine Science 85:121-132

Gilmour JP, Smith LD, Heyward AJ, Baird AH, Pratchett MS (2013) Recovery of an Isolated Coral Reef System Following Severe Disturbance. Science 340:69

Glynn PW, Wellington GM, Birkeland C (1979) Coral reef growth in the Galápagos: limitation by sea urchins. Science 203:47-49

Goreau T, McClanahan TR, Hayes R, Strong A (2000) Conservation of coral reefs after the 1998 global bleaching event. Conservation Biology 14:5-15

Graham NA, Jennings S, MacNeil MA, Mouillot D, Wilson SK (2015) Predicting climate-driven regime shifts versus rebound potential in coral reefs. Nature 518:94-97

Graham NAJ, Nash KL (2013) The importance of structural complexity in coral reef ecosystems. Coral Reefs 32:315-326

Graham NAJ, Nash KL, Kool JT (2011) Coral reef recovery dynamics in a changing world. Coral Reefs 30:283-294

Graham NAJ, Wilson SK, Jennings S, Polunin NVC, Bijoux JP, Robinson J (2006) Dynamic fragility of oceanic coral reef ecosystems. Proceedings of the National Academy of Sciences 103:8425-8429

Graham NAJ, Wilson SK, Jennings S, Polunin NVC, Robinson JAN, Bijoux JP, Daw TM (2007) Lag Effects in the Impacts of Mass Coral Bleaching on Coral Reef Fish, Fisheries, and Ecosystems. Conservation Biology 21:1291-1300

Harris A, Wilson S, Graham N, Sheppard C (2014) Scleractinian coral communities of the inner Seychelles 10 years after the 1998 mortality event. Aquatic Conservation: Marine and Freshwater Ecosystems 24:667-679

Hughes TP, Jackson JBC (1985) Population Dynamics and Life Histories of Foliaceous Corals. Ecological Monographs $55: 141-166$

Hughes TP, Tanner JE (2000) Recruitment failure, life histories and long-term decline of Caribbean corals. Ecology 81:2250-2263

Hughes TP, Graham NAJ, Jackson JBC, Mumby PJ, Steneck RS (2010) Rising to the challenge of sustaining coral reef resilience. Trends in Ecology \& Evolution 25:633-642

Hughes TP, Baird AH, Dinsdale EA, Moltschaniwskyj N, Pratchett MS, Tanner JE, Willis BL (2000) Supply-side ecology works both ways: the link between benthic adults, fecundity and larval recruits. Ecology 81:2241-2249

Hughes TP, Rodrigues MJ, Bellwood DR, Ceccarelli D, HoeghGuldberg O, McCook L, Moltschaniwskyj N, Pratchett MS, Steneck RS, Willis B (2007) Phase Shifts, Herbivory, and the Resilience of Coral Reefs to Climate Change. Current Biology 17:360-365

Hughes TP, Anderson KD, Connolly SR, Heron SF, Kerry JT, Lough JM, Baird AH, Baum JK, Berumen ML, Bridge TC, Claar DC, Eakin CM, Gilmour JP, Graham NAJ, Harrison H, Hobbs J-PA, Hoey AS, Hoogenboom M, Lowe RJ, McCulloch MT, Pandolfi JM, Pratchett M, Schoepf V, Torda G, Wilson SK (2018) Spatial and temporal patterns of mass bleaching of corals in the Anthropocene. Science 359:80-83

Hughes TP, Kerry JT, Alvarez-Noriega M, Alvarez-Romero JG, Anderson KD, Baird AH, Babcock RC, Beger M, Bellwood DR, Berkelmans R, Bridge TC, Butler IR, Byrne M, Cantin NE, Comeau S, Connolly SR, Cumming GS, Dalton SJ, Diaz-Pulido G, Eakin CM, Figueira WF, Gilmour JP, Harrison HB, Heron SF, Hoey AS, Hobbs JA, Hoogenboom MO, Kennedy EV, Kuo CY, Lough JM, Lowe RJ, Liu G, McCulloch MT, Malcolm HA, 
McWilliam MJ, Pandolfi JM, Pears RJ, Pratchett MS, Schoepf V, Simpson T, Skirving WJ, Sommer B, Torda G, Wachenfeld DR, Willis BL, Wilson SK (2017) Global warming and recurrent mass bleaching of corals. Nature 543:373-377

Jennings S, Grandcourt EM, Polunin NVC (1995) The effects of fishing on the diversity, biomass and trophic structure of Seychelles' reef fish communities. Coral Reefs 14:225-235

Johns KA, Emslie MJ, Hoey AS, Osborne K, Jonker MJ, Cheal AJ (2018) Macroalgal feedbacks and substrate properties maintain a coral reef regime shift. Ecosphere 9:1-15

Jompa J, McCook LJ (2003) Coral-algal competition: macroalgae with different properties have different effects on corals. Marine Ecology Progress Series 258:87-95

Kohler KE, Gill SM (2006) Coral Point Count with Excel extensions (CPCe): A Visual Basic program for the determination of coral and substrate coverage using random point count methodology. Computers \& Geosciences 32:1259-1269

Letourneur Y, Kulbicki M, Labrosse P (1998) Length-weight relationship of fishes from coral reefs and lagoons of New Caledonia: an update. Naga 21:39-46

Littler MM, Littler DS (1984) Models of tropical reef biogenesis: the contribution of algae. In: Round FE, Chapman DJ (eds) Progress in phycological research. Biopress, Bristol, pp 323-364

Lokrantz J, Nyström M, Thyresson M, Johansson C (2008) The nonlinear relationship between body size and function in parrotfishes. Coral Reefs 27:967-974

McCook LJ, Jompa J, Diaz-Pulido G (2001) Competition between corals and algae on coral reefs: a review of evidence and mechanisms. Coral Reefs 19:400-417

Milligan KLD, DeWreede RE (2000) Variations in holdfast attachment mechanics with developmental stage, substratum-type, season, and wave-exposure for the intertidal kelp species Hedophyllum sessile (C. Agardh) Setchell. Journal of Experimental Marine Biology and Ecology 254:189-209

Morrison L, Feely M, Stengel DB, Blamey N, Dockery P, Sherlock A, Timmins E (2009) Seaweed attachment to bedrock: biophysical evidence for a new geophycology paradigm. Geobiology 7:477-487

Mumby P, Steneck R (2008) Coral reef management and conservation in light of rapidly evolving ecological paradigms. Trends in Ecology \& Evolution 23:555-563

Mumby PJ, Bejarano S, Golbuu Y, Steneck RS, Arnold SN, van Woesik R, Friedlander AM (2013) Empirical relationships among resilience indicators on Micronesian reefs. Coral Reefs 32:213-226

Norström AV, Lokrantz J, Nyström M, Yap HT (2006) Influence of dead coral substrate morphology on patterns of juvenile coral distribution. Marine Biology 150:1145-1152

Norström AV, Nyström M, Jouffray J-B, Folke C, Graham NAJ, Moberg F, Olsson P, Williams GJ (2016) Guiding coral reef futures in the Anthropocene. Frontiers in Ecology and the Environment 14:490-498

Nugues MM, Smith GW, Hooidonk RJ, Seabra MI, Bak RPM (2004) Algal contact as a trigger for coral disease. Ecology Letters 7:919-923

Nyström M, Norström AV, Blenckner T, de la Torre-Castro M, Eklöf JS, Folke C, Österblom H, Steneck RS, Thyresson M, Troell M (2012) Confronting feedbacks of degraded marine ecosystems. Ecosystems 15:695-710

Pinheiro J, Bates D, DebRoy S, Sarkar D and R Core Team (2018). nlme: Linear and Nonlinear Mixed Effects Models. R package version 3.1-137

Polunin NVC, Roberts CM (1993) Greater biomass and value of target coral-reef fishes in two small Caribbean marine reserves. Marine Ecology Progress Series 100:167-176
Poray AK, Carpenter RC (2013) Distributions of coral reef macroalgae in a back reef habitat in Moorea, French Polynesia. Coral Reefs 33:67-76

R-Core-Team (2018) R: a language and environment for statistical computing. R Foundation for Statistical Computing, Vienna

Rasher DB, Hay ME (2010) Chemically rich seaweeds poison corals when not controlled by herbivores. Proceedings of the National Academy of Sciences of the United States of America 107:9683-9688

Rasher DB, Stout EP, Engel S, Kubanek J, Hay ME (2011) Macroalgal terpenes function as allelopathic agents against reef corals. Proceedings of the National Academy of Sciences 108:177726-177731

Risk MJ (2014) Assessing the effects of sediments and nutrients on coral reefs. Current Opinion in Environmental Sustainability 7:108-117

Ritson-Williams R, Paul VJ, Arnold SN, Steneck RS (2010) Larval settlement preferences and post-settlement survival of the threatened Caribbean corals Acropora palmata and A. cervicornis. Coral Reefs 29:71-81

Robinson JPW, Wilson S, Robinson J, Gerry C, Govinden R, Lucas J, Assan C, Jennings S, Graham NAJ (2018) Productive instability of coral reef fisheries after climate-driven regime shifts. Nature Ecology and Evolution

Rogers A, Blanchard JL, Mumby PJ (2014) Vulnerability of coral reef fisheries to a loss of structural complexity. Current Biology 24:1000-1005

Roth MS, Knowlton N (2009) Distribution, abundance, and microhabitat characterization of small juvenile corals at Palmyra Atoll. Marine Ecology Progress Series 376:133-142

Schielzeth H (2010) Simple means to improve the interpretability of regression coefficients. Methods in Ecology and Evolution $1: 103-113$

Sheppard CRC, Spalding MD, Bradshaw C, Wilson S (2002) Erosion vs. Recovery of Coral Reefs after 1998 El Niño: Chagos Reefs, Indian Ocean. Ambio 31:40-48

Smith JE, Shaw M, Edwards RA, Obura D, Pantos O, Sala E, Sandin SA, Smriga S, Hatay M, Rohwer FL (2006) Indirect effects of algae on coral: algae-mediated, microbe-induced coral mortality. Ecology letters 9:835-845

Steneck RS, Mumby PJ, MacDonald C, Rasher DB, Stoyle G (2018) Attenuating effects of ecosystem management on coral reefs. Science Advances: EAAO5493

Tanner JE (1995) Competition between scleractinian macroalgae: An experimental corals and investigation of coral growth, survival and reproduction. Journal of Experimental Marine Biology and Ecology 190:151-168

Thomsen MS (2004) Species, thallus size and substrate determine macroalgal break force and break location in a low-energy softbottom lagoon. Aquatic Botany 80:153-161

Vergés A, Vanderklift MA, Doropoulos C, Hyndes GA (2011) Spatial Patterns in Herbivory on a Coral Reef Are Influenced by Structural Complexity but Not by Algal Traits. PLoS ONE 6:e17115

Vermeij MJA, Dailer ML, Smith CM (2011) Crustose coralline algae can suppress macroalgal growth and recruitment on Hawaiian coral reefs. Marine Ecology Progress Series 422:1-7

Williams ID, Polunin NVC, Hendrick VJ (2001) Limits to grazing by herbivorous fishes and the impact of low coral cover on macroalgal abundance on a coral reef in Belize. Marine Ecology Progress Series 222:187-196

Wilson SK, Graham NA, Polunin NVC (2007) Appraisal of visual assessments of habitat complexity and benthic composition on coral reefs. Marine Biology 151:1069-1076 
Wilson SK, Dolman AM, Cheal AJ, Emslie MJ, Pratchett MS, Sweatman HPA (2008) Maintenance of fish diversity on disturbed coral reefs. Coral Reefs 28:3-14

Wilson SK, Graham NAJ, Fisher R, Robinson J, Nash K, Chong-Seng K, Polunin NVC, Aumeeruddy R, Quatre R (2012) Effect of Macroalgal Expansion and Marine Protected Areas on Coral Recovery Following a Climatic Disturbance. Conservation Biology 26:995-1004

Yadav S, Rathod P, Alcoverro T, Arthur RJCR (2016) "Choice" and destiny: the substrate composition and mechanical stability of settlement structures can mediate coral recruit fate in postbleached reefs. 35:211-222
Zeileis A, Kleiber C, Jackman S (2008). Regression Models for Count Data in R. Journal of Statistical Software 27(8), R package version 1.5.2

Zuur A, Ieno E, Walker N, Saveliev A, Smith G (2009) Mixed effects models and extensions in ecology with R. Gail M, Krickeberg K, Samet JM, Tsiatis A, Wong W, editors. New York, NY: Spring Science and Business Media

Zuur AF, Saveliev AA, Ieno EN (2012) Zero Inflated Models and Generalized Linear Mixed Models with R. Highland Statistics Ltd., Newburgh, UK

Publisher's Note Springer Nature remains neutral with regard to jurisdictional claims in published maps and institutional affiliations. 